https://helda.helsinki.fi

\title{
Antioxidant supplements and mortality
}

\section{Hemilä, Harri}

2007

Hemilä , H 2007 , ' Antioxidant supplements and mortality ', JAMA : The Journal of the

American Medical Association , vol. 298 , no. 4 , pp. 401-401 . https://doi.org/10.1001/jama.298.4.401-a

http://hdl.handle.net/10138/223747

https://doi.org/10.1001/jama.298.4.401-a

publishedVersion

Downloaded from Helda, University of Helsinki institutional repository.

This is an electronic reprint of the original article.

This reprint may differ from the original in pagination and typographic detail.

Please cite the original version. 
Third, dying from a supplement after only a few months of use seems biologically implausible. The finding that supplementation duration had no effect on total mortality diminishes the likelihood that these micronutrients increase the risk of death.

Fourth, the conclusions are based predominantly on findings from the "low-bias risk" subgroup defined by methodological quality assessment. The authors note that methodological details might not have been reported from studies implemented in ways that met the quality assessment criteria so that a lack of reporting might have been mistaken as a lack of high quality. More importantly, the quality of trial implementation may cause even greater bias. For example, a study reporting a $60 \%$ dropout rate is more likely to produce biased results than a study with no dropouts that does not report on dropouts. Adherence to study supplement use and self-selection into supplementation can also create bias. ${ }^{2-4}$ These issues are particularly relevant to trials conducted in recent years when self-selected supplement use was prevalent, and the low-bias risk trials defined by Bjelakovic et al tended to have been conducted more recently than the high-bias risk trials.

\author{
Han-Yao Huang, PhD, MPH \\ han-yao_huang@merck.com \\ Steven Teutsch, MD, MPH \\ Outcomes Research and Management \\ Merck \& Co, Inc \\ West Point, Pennsylvania \\ Eric Bass, MD, MPH \\ Department of Medicine \\ Johns Hopkins School of Medicine \\ Baltimore, Maryland
}

Financial Disclosures: Drs Huang and Teutsch reported that they are full-time em ployees of Merck \& Co, Inc, which does not manufacture or sell dietary supplements. Dr Bass reported no disclosures.

1. Bjelakovic G, Nikolova D, Gluud LL, Simonetti RG, Gluud C. Mortality in randomized trials of antioxidant supplements for primary and secondary prevention: systematic review and meta-analysis. JAMA. 2007;297(8):842-857.

2. Huang HY, Caballero B, Chang S, et al. Multivitamin/Mineral Supplements and Prevention of Chronic Disease. Rockville, MD: Agency for Healthcare Research and Quality; 2006. Evidence Report/Technology Assessment No. 139. http: //www.ahrq.gov/clinic/evrptpdfs.htm\#multivit. Accessed March 20, 2007.

3. Lee IM, Cook NR, Gaziano JM, et al. Vitamin E in the primary prevention of cardiovascular disease and cancer: the Women's Health Study: a randomized controlled trial. JAMA. 2005;294(1):56-65.

4. Jackson RD, LaCroix AZ, Gass M, et al. Calcium plus vitamin D supplementation and the risk of fractures. N Engl J Med. 2006;354(7):669-683.

To the Editor: Dr Bjelakovic and colleagues ${ }^{1}$ showed that there is no evidence from randomized trials that antioxidant supplements reduce mortality. However, the authors did not consider that the effects might vary among different population subgroups so that an average for a large group of people could be misleading.

Analyses of the large-scale Alpha-Tocopherol BetaCarotene (ATBC) Cancer Prevention Study found substantial divergence in the effect of $50 \mathrm{mg} / \mathrm{d}$ of vitamin $\mathrm{E}$ on common cold incidence in elderly men. Among participants 72 years or older, who smoked heavily, and lived out- side cities, use of vitamin $\mathrm{E}$ increased common cold incidence by $58 \%$ (95\% confidence interval [CI], 23\%-101\%; 0.83 vs 0.53 colds per year), whereas in less-smoking citydwellers it reduced common cold incidence by $46 \%$ (95\% CI, $-20 \%$ to $-63 \% ; 0.47$ vs 0.86 colds per year). ${ }^{2}$ The effect of vitamin $E$ on the incidence of pneumonia also diverged so that the risk increased or decreased depending on the age of smoking initiation. ${ }^{3}$ Furthermore, among participants who exercised during leisure, vitamin $\mathrm{E}$ reduced the incidence of pneumonia by $50 \%$ ( $95 \%$ CI,$-16 \%$ to $-70 \%$; 1.5 vs 3.0 cases of pneumonia per 1000 person-years); however, the number needed to treat was high, so that 667 people would need to take vitamin E for one year to prevent one episode of pneumonia. ${ }^{4}$ Although the practical significance of these findings is uncertain, they indicate that subgroups of people may benefit, or may be harmed from vitamin E supplementation even though the average effect in the population is nil.

The widespread use of vitamin E supplements should be discouraged because there is no evidence that the general population would benefit from such practice. However, the subgroup findings of the ATBC Study warrant further research to characterize the small groups of people for whom vitamin E supplementation may be beneficial.

Harri Hemilä, MD, PhD

harri.hemila@helsinki.fi

Department of Public Health

University of Helsinki

Helsinki, Finland

Financial Disclosures: None reported.

1. Bjelakovic G, Nikolova D, Gluud LL, Simonetti RG, Gluud C. Mortality in randomized trials of antioxidant supplements for primary and secondary prevention: systematic review and meta-analysis. JAMA. 2007;297(8):842-857.

2. Hemilä H, Virtamo J, Albanes D, Kaprio J. The effect of vitamin E on common cold incidence is modified by age, smoking and residential neighborhood. J Am Coll Nutr. 2006;25(4):332-339.

3. Hemilä H, Virtamo J, Albanes D, Kaprio J. Vitamin E and beta-carotene supplementation and hospital-treated pneumonia incidence in male smokers. Chest. 2004; 125(2):557-565.

4. Hemilä H, Kaprio J, Albanes D, Virtamo J. Physical activity and the risk of pneumonia in male smokers administered vitamin $\mathrm{E}$ and $\beta$-carotene. Int J Sports Med. $2006 ; 27(4): 336-341$

To the Editor: We believe that the approach used in the metaanalysis of mortality in randomized trials of antioxidant supplements by Dr Bjelakovic and colleagues ${ }^{1}$ erred in several important ways, probably resulting in biased conclusions.

First, the Linxian General Population Nutrition Intervention Trial (NIT) ${ }^{2}$ was misclassified as a "trial with high risk of bias." This double-blind placebo-controlled trial of 29584 persons contained all the attributes described by the authors as defining trials with low risk of bias: more than $60 \%$ of the target population was enrolled and computerrandomized, and participant characteristics were virtually identical across all supplement groups (no selection bias); all pill bottles were masked throughout the trial (adequate allocation concealment and blinding); all participants were 